\title{
Inhaltsverzeichnis.
}

Naturbilder.

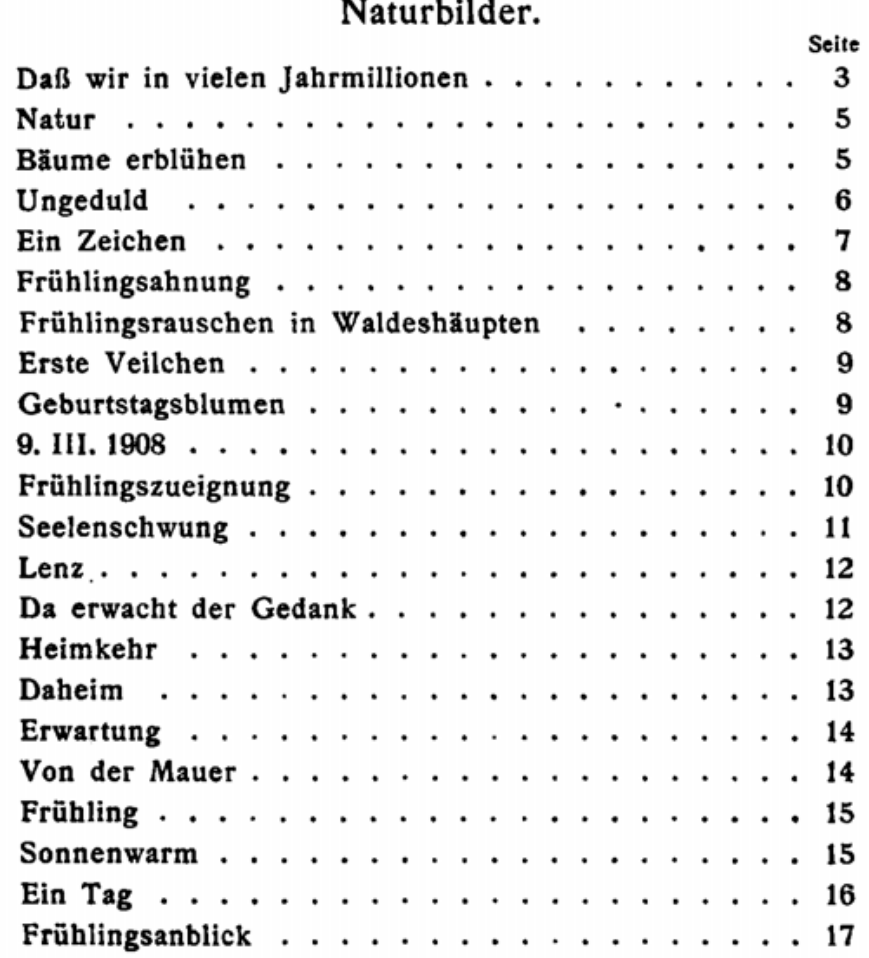


Ode .................... 18

Heit'rer Duft . . . . . . . . . . . . . . . 19

Frühlingshymne ............... . 19

Wie Schwalben................. 20

Entmutigt . . . . . . . . . . . . . . 21

Frühe ................... . 22

Auf hoher Bergwiese . . . . . . . . . . . 22

Blumenstrauß . . . . . . . . . . . . . 23

Nach sonnig durchwandertem . . . . . . . . . 23

Spätabend ............... . . . 24

Luna . . . . . . . . . . . . . . . . . 24

Frühlingsbild . . . . . . . . . . . . . . 25

Tauchen deine Sehnsüchte . . . . . . . . . 25

Ein Sommertag (volkstümliches Fest in Heidelberg) . 26

Dort . . . . . . . . . . . . . . . . . . 27

Ein Maitag ................. . 27

Sommer . . . . . . . . . . . . . . . 28

Mittag . . . . . . . . . . . . . . 28

Liebesboote . . . . . . . . . . . . . 29

Einsam . . . . . . . . . . . . . . . . 29

Gefangenschaft . . . . . . . . . . . . 30

Wie ich an dem Fenster . . . . . . . . . . . 30

Überall . . . . . . . . . . . . . . . . . . 31

Sonnendurchwärmt .. . . . . . . . . . . 31

Planera kiaki . . . . . . . . . . . . . . 32

Die Natur betrachtend . . . . . . . . . . 32

Friede . . . . . . . . . . . . . 33

Beim Einbruch der Nacht . . . . . . . . . . 33

Am späten Abend . . . . . . . . . . . . . 34

Auf Sommers abgepflückten Hängen . . . . . . . 34

Trüber Tag . . . . . . . . . . . . . . . . . . 34

Aufstieg . . . . . . . . . . . . . . . 35 
Herbst . . . . . . . . . . . . . . . . 36

Himmelsbild . . . . . . . . . . . . . . 36

Abglanz (Degerloch 1907) . . . . . . . . . . 37

Luftfahrer . . . . . . . . . . . . . . . 38

Wehmütig zartes Goldlaub . . . . . . . . . . 38

Versenkung . . . . . . . . . . . . . 39

Des Teiches graue Fläche. . . . . . . . . . . . . 39

Erlöschen ... . . . . . . . . . . . . 4 40

Durch die angehauchte . . . . . . . . . . 40

Spiegelbild . . . . . . . . . . . . . . 4 41

Doch ........ . . . . . . . . . . 41

Fremde ................... 42

Still für sich . . . . . . . . . . . . . . 4 42

Wahrzeichen I, II, III, IV . . . . . . . . . . 43-44

Abend . . . . . . . . . . . . . . . . 45

Müde ............ . . . . . . . 45

So wie den herbsılichen Bäumen . . . . . . . . . . 46

Herbst (letztes Gedicht. Nov. 1910) . . . . . . . . . 46

Einsamer Stand . . . . . . . . . . . . . . 47

Brandung . . . . . . . . . . . . . . . 48

Ein Gang . . . . . . . . . . . . . . . . . 49

Mehr und mehr ................ . 50

Schneefall ................. . 51

Seelenwinter . . . . . . . . . . . . . . 52

Hinter Schneegezäun . . . . . . . . . . 53

Winterlust ................. . 54

Eingeschneit . . . . . . . . . . . . . . 54

Eine Stunde . . . . . . . . . . . . . . 55

Frage .. . . . . . . . . . . . . . 56

Noch Winter.................56

An die Schönheit............... . 57 
Die ersten Glöcklein.

Mein Ahne .............. . . 61

Sternblümlein .............663

Durch die Blume. . . . . . . . . . 63

Volkslied . . . . . . . . . . . . . 64

Nachthimmel . . . . . . . . . . . . . 64

Im Quell . . . . . . . . . . . . . 65

Zu einem Schlüsselkorb . . . . . . . . 66

Des Tones Dauer. . . . . . . . . . . 66

Schwermutsvoll . . . . . . . . . . . . 67

Im Winter ............... . . . . . .

Im Brunnen . . . . . . . . . . . . . 68

Himmelsleiter . . . . . . . . . . . . . 69

Da war's am Abend. . . . . . . . . . . 69

Ach, nirgends find ich meine Ruh. . . . . . 70-71

Märchen . . . . . . . . . . . 72

Nacht .................. . . 72

Liebeswellen . . . . . . . . . . 73

Gesellschaft . . . . . . . . . . . . . 74

Im Saale brennen die Lüster . . . . . . . . . 74

Langeweile . . . . . . . . . . . . 75

Wo die liebsten Blumen wachsen .......75

Sturm .................. . . 76

Von den ersten Sonnenstrahlen ....... . 76

Ich hab dich gebeten zu kommen . . . . . . . 77

Wie die kleinen Sommerfliegen ......... 77

Ach, ich dachte mir das Leben . . . . . . . 78

Noch ist des Vergessens . . . . . . . . . 79

Aus dem Zyklus Liebesklage.

Violen färbt sich . . . . . . . . . . 83

Ach, es schneit ..............83 
Ihr süßen Gestalten . . . . . . . . . 84

Buntfarbig, wie allerhand Spielzeug . . . . . 85-86

Veilchenglöcklein schauen .......... 87

Sommer ist's . . . . . . . . . . . . . . 87

Morgens . . . . . . . . . . . . . 88

Wie der West daherfährt . . . . . . . . 89

Aus den Rhapsodien.

In die Schenke des Lebens . . . . . . . . 93

Lieb bist du . . . . . . . . . . . . . . . 94

Ich liebe die süße Geliebte . . . . . . . . . 95

Schön bist du kühler Hauch der Nacht . . . . . . 96

Einsam geh ich . . . . . . . . . . . . . . 97

Ich war nicht zur Knechtschaft geboren. . . . 98-83

Traurigkeit ist in mir . . .. . . . . . . . . 100

Meine Gedanken . . . . . . . . . . . 101-103

Aus meiner Seele besten Stunden . . . . . . . ,04

Du fliehst von mir Jugend . . . . . . . . . . . 104

Einen Zaubermantel . . . . . . . . . . . 105

Versunken seid ihr silbernen Schleier . . . . . 105

Aus der Tröstung.

Fragment . . . . . . . . . . 109-111

Der Gigant ... . . . . . . . . . . . . 112

Frühlingserwachen . . . . . . . . . . . 113

Weine nicht . . . . . . . . . . . . 113

Mit Rosen . . . . . . . . . . . . . . . 114

Wald und Wiesen seh ich grünen . . . . . . 114

Im Sommer . . . . . . . . . . . . . . . 115

Da erwacht der Gedank' . . . . . . . . . . 115

Abendstille (Übersetzung aus dem Griechischen) . 115

Alles schläft . . . . . . . . . . . . . 116

Hans Baer, Dichtungen. 
Meines Herzens tiefe Wünsche . . . . . . . 116

Chorus hymenaeus . . . . . . . . . . . 117

Das ist der Tag . . . . . . . . . . . . . 118

Im Mai . . . . . . . . . . . . . . . . . 119

Ich hab zu Grab getragen . . . . . . . . . . . 119

Naht euch ihr stillen Geister. . . . . . . . 120

Heidelberg . . . . . . . . . . . . . . . 121

Auf der Schönfeldspitze . . . . . . . . . . 123

Hoher Alpsee . . . . . . . . . . . . . . . 123

Die Amsel flötet ihre Lieder . . . . . . . . . 124

Gedenken . . . . . . . . . . . . . . . 124

Ach süßer Berg. . . . . . . . . . . . . . . 125

Les' ich der Alten einen . . . . . . . . . . 125

Im Garten . . . . . . . . . . . . . . . . 126

Blickst zu den Sternen du auf
Allen Sternen $\quad\left\{\begin{array}{c}\text { Übersetzungen } \\ \text { aus dem }\end{array}\right\} 128$

Schweigt ihr rauschenden Eichen Griechischen ${ }_{129}$

Zu Wanderers Sturmlied . . • • . . . . . . . 129

Euphorion . . . . . . . . . . . . . . . . 130

Holder Wunsch . . . . . . . . . . . . . . 130

Junius . . . . . . . . . . . . . . . . . 131

Bei Sonnenuntergang . . . . . . . . . . . 132

Vermutung . . . . . . . . . . . . . 132

Nähe (des Hoffnungslosen) . . . . . . . . . 133

Aus dem Odenwald . . . . . . . . . . . . . 134

Im September (Resedenblond) . . . . . . . . . 134

Am Rhein (zu Berg!) . . . . . . . . . . . 135

Am Fenster . . . . . . . . . . . . . 137

Năhe (Deingedenken) . . . . . . . . . . . 138

Geisterstimmen . . . . . . . . . . . . 139

Traum . . . . . . . . . . . . . . 140

Liebe (Eros) . . . . . . . . . . . . . . . . 141 
An - - - . . . . . . . . . . . . . . 142

Trost . . . . . . . . . . . . . . . . . . . 144

Befreiung . . . . . . . . . . . . 145

Geheimnisvoll, aus deines Briefes Bogen . . . . . 146

Ithaka . . . . . . . . . . . . . . . . . 146

An - - . . . . . . . . . . . . . 147

Threnodie . . . . . . . . . . . . . . . . 147

Ja man ersieht nur zu bald . . . . . . . 148

Wer seine Grenzen nicht kennt . . . . . . 148

Fünf Gedichte zu einem Bilderbuch.

(1908)

Morgen . . . . . . . . . . . . . . . 151

Tanz . . . . . . . . . . . . . . 152

Am Teich . . . . . . . . . . . . . . . . 153

Heimfahrt . . . . . . . . . . . . 154

Nacht . . . . . . . . . . . . 155 



\title{
VERLAG VON KARL J. TRÜBNER IN STRASSBURG
}

Vom gleichen Verfasser erschienen früher:

\section{Grundriß eines Systems der ästhetischen Entwicklung}

\author{
ron \\ Dr. Hans Baer.
}

8. VII, 147 S. 1913. M. 3.-, in Leinwand gebunden M. 4.-.

Inhalt: Vorrede. Vorwort. I. Das Problem der isthetischen Entwick lung. - II. Das Entwicklungsproblem in der Geschichte der Aesthetik. III. Einleitung zur Phänomenologie. - IV. Phänomenologie des ästhetischen Bewusstseins: 1. Die bildnerische Entwicklung (Die ersten Anfänge der bildenden Kunst; Die ägyptische Kunst; Die Kunst des griechischen Kulturkreises; Byzantinisch-altchristlich, sarazenische Kunst; Barbarische Stile; China; Die neueuropäische Entwickiung). 2. Die musikalische Entwicklung. V. Rückblick.

„Aus dem Nachlaß eines, leider zu früh verschiedenen, jungen Gelehrten wurde vorliegendes Werk durch seinen Freund Dr. Georg Mehlis veröffentlicht. ,Ich habe noch viel zu sagen', das sind die letzten Worte des Sterbenden gewesen, und ihre Wahrheit klingt uns aus dem ganzen Werkchen entgegen. Tiefe Fragen werden aufgeworfen und oft deren Lösung nur streiflichtartig angedeutet Man fühlt, daß der Verfasser gehofft, in einer größeren Reihe von Werken das geben zu dürfen, was sein Innerstes bewegte. Leider war dies ihm nicht vergönnt; sein Leben ist vollendet, sein Werk jedoch erst begonnen. So liegt dies Bändehen als die erste und leider einzige Frucht tiefen, wissenschaftlichen Erkenntnisstrebens vor uns. Die Frage nach den Gesetzen der ästhetischen Entwicklung wird vom Verfasser hier zu lösen versucht. Nicht nur die Frage nach der Gesetzmäßigkeit des Gewordenen wird aufgeworfen, sondern die nach der Gesetzmäßigkeit des Werdeprozesses selbst wird gestellt und darüber hinaus nach den für die gesamte Kunstentwicklung geltenden Gesetzen gefragt. Dabei ist sich der Verfasser wohl bewußt, daß hier keine Gesetzmäßigkeit im naturwissen. schaftlichen Sinn aufgezeigt werden soll, sondern es sich um die Aufweisung einer bestimmten Abfolge wertbildender Funktionen handelt, die den Gang isthetischer Entwicklung leiten. ...."

Strapburger Post vom 30. Nov. 1913.

Siebe auch nächate Seite. 


